\title{
Maternal birth trauma and its consequences: time to raise awareness
}

\author{
R. M. Freeman ${ }^{1}$ • J. W. de Leeuw ${ }^{2}$ - P. D. Wilson ${ }^{3}$ \\ Published online: 17 June 2021 \\ (C) The International Urogynecological Association 2021
}

This editorial is an introduction to the Themed Edition on obstetric pelvic floor trauma and its consequences.

The rate of obstetric pelvic floor trauma and the consequences of urinary and faecal incontinence and pelvic organ prolapse have increased in recent years. Although one can understand that preventing these might not be a priority for many obstetricians and midwives compared with preventing stillbirth, pre-term labour or pre-eclampsia, pelvic organ prolapse and incontinence are nonetheless a significant public health burden. This involves considerable personal and financial costs for the patient, healthcare providers and society.

The understanding of the pathophysiology of obstetric pelvic floor trauma has grown in recent years, with evidence from imaging techniques well described in the paper in this edition by H.P. Dietz [1] and modelling studies of the pelvic floor during labour and head expulsion in a paper by Cechova $\mathrm{H}$ [2].

Levator avulsion, a high-risk factor for short and long-term pelvic floor dysfunction, has been seen in ultrasound and MRI studies [3]. One of the main risk factors is instrumental delivery, particularly forceps, and this is well described in the paper by de Leeuw and Daly [4].

Unsurprisingly, the consequences of such trauma have significant physical and psychological consequences for young women that can last a lifetime.

It appears they are not routinely informed of these risks, despite several legal rulings, and their right to make informed choices is well described in the paper written by a legal expert, L. Sutherland [5].

Qualitative studies suggest that women want to know their risk of developing pelvic floor dysfunction to help make

R. M. Freeman

bobfreeman@virginmedia.com

1 University Hospitals Plymouth NHS Trust, Plymouth, UK

2 Department of Obstetrics and Gynaecology, Ikazia Ziekenhuis, Rotterdam, the Netherlands

3 University of Otago, Dunedin, New Zealand decisions about childbirth. They also report that knowing their risk would motivate them to undertake preventative strategies such pelvic floor muscle training (PFMT) [6]. This desire for information is further supported in the paper by M. Jurczuk [7]. as part of a "care bundle" that has been shown to reduce the rate of obstetric anal sphincter injury (OASI), with no increase in caesarean section rate.

Providing women with their individual risk has the potential to reassure the majority at a lower risk and reduce caesarean section requests, while advising the smaller number at a higher risk about preventative strategies. The UR-CHOICE risk calculator has been developed for that purpose and is described by E. Jelovsek in this edition [8].

This highlights the need for antenatal risk assessment and providing women with information on which to make informed choices.

For example, although planned caesarean section can be protective for pelvic organ prolapse and urinary incontinence [9], potential risks require explanation, as in the paper by $\mathrm{J}$. King [10].

Pelvic floor muscle training is arguably less controversial and should be offered to all women during and after pregnancy as it can prevent urinary incontinence in late pregnancy and postpartum, and also reduce prolapse symptoms and the need for further treatment [11].

S. Woodley and E. Hay-Smith provide the important evidence base and advice on PFMT implementation in a paper in this edition [12].

Hopefully, this Themed Edition will raise awareness of the consequences and effects of obstetric pelvic floor trauma, not just amongst readers of the IUJ but for midwives, obstetricians and especially women either during pregnancy, or during the planning of one, who can then be risk assessed, informed and empowered to make informed choices.

Declarations R.M. Freeman: Chairman of OASI 2 Care Bundle Independent Advisory Group, Co-Inventor of "Episcissors-60" (no financial interests or fees); J.W. de Leeuw: Chairman of the IUGA Obstetric Pelvic Floor Trauma Special Interest Group; P.D. Wilson: no disclosures. 


\section{References}

1. Dietz HP. Ultrasound imaging of maternal birth trauma. Int Urogynecol J. 2021. https://doi.org/10.1007/s00192-020-04669-8.

2. Cechova H, Kalis V, Havelkova L, et al. Finite element modeling of maximum stress in pelvic floor structures during the head expulsion (FINESSE) study. Int Urogynecol J. 2021. https://doi.org/10.1007/ s00192-021-04769-z.

3. Friedman T, Eslick GD, Dietz HP. Delivery mode and the risk of levator muscle avulsion: a meta-analysis. Int Urogynecol J. 2019;30:901-7.

4. De Leeuw, JW, Daly O. Forceps and vacuum: one goal, two entities. Int Urogynecol J. 2021. https://doi.org/10.1007/s00192-02104866-z.

5. Sutherland L. The right of patients to make autonomous choices. Int Urogynecol J. 2021.https://doi.org/10.1007/s00192-021-04882-z.

6. Bugge $\mathrm{C}$, Strachan $\mathrm{H}$, Cheyne $\mathrm{H}$, Wilson $\mathrm{D}$ et al. Investigating pregnant women's and heathcare professional's views about knowing a woman's individual risk of future pelvic floor dysfunction: A feasibility study for a randomised controlled trial. Proceedings of UKCS meeting $2020 \mathrm{https} / / \mathrm{ukcs}$.uk.net/.

7. Jurczuk M, Bidwell P, Gurol-Urganci I, et al. The OASI care bundle quality improvement project: lessons learned and future direction. Int Urogynecol J. 2021. https://doi.org/10.1007/s00192-02104786-y.
8. Jelovsek JE. Clinical prediction is at the heart of preventing birth trauma and pelvic floor disorders for individual women. Int Urogynecol J. 2021. https://doi.org/10.1007/s00192-021-04797-9.

9. Keag OE, Norman JE, Stock SJ. Long-term risks and benefits associated with cesarean delivery for mother, baby, and subsequent pregnancies: systematic review and meta-analysis. PLoS Med. 2018;15:e1002494.

10. King J. Are there adverse outcomes for child health and development following caesarean section delivery? Can we justify using elective caesarean section to prevent obstetric pelvic floor damage? Int Urogynecol J. 2021. https://doi.org/10.1007/s00192-02104781-3.

11. Woodley SJ, Boyle R, Cody JD, et al. Pelvic floor muscle training for prevention and treatment of urinary and faecal incontinence in antenatal and postnatal women. Cochrane Database Syst Rev. 2017; 12:CD007471.

12. Woodley SJ, Hay-Smith EJC. Narrative review of pelvic floor muscle training for childbearing women - why, when, what, and how. Int Urogynecol J. 2021. https://doi.org/10.1007/s00192-02104804-z.

Publisher's note Springer Nature remains neutral with regard to jurisdictional claims in published maps and institutional affiliations. 